\title{
Licenciatura em Matemática da Universidade do Estado do Pará - UEPA e a formação para o trabalho docente no contexto rural de Conceição do Araguaia - PA
}

Kamilla Ferreira da Silva ${ }^{1}$, Idemar Vizolli ${ }^{2}$

${ }^{1}$ Universidade Federal do Sul e Sudeste do Pará - UNIFESSPA. Instituto de Ciências Exatas (ICE). Avenida dos Ipês, s./n., Cidade Universitária. Marabá - Pará. Brasil. ${ }^{2}$ Universidade Federal do Tocantins - UFT.

Autor para correspondência/Author for correspondence: kamilla.silva@unifesspa.edu.br

\begin{abstract}
RESUMO. Este artigo teve como objetivo verificar que aspectos da prática docente no contexto rural são contemplados no Projeto Pedagógico do Curso (PPC) do curso de Licenciatura em Matemática da Universidade do Estado do Pará - UEPA. Para tanto desenvolveu-se uma pesquisa descritiva e documental com abordagem qualitativa pautada na análise do histórico do ordenamento jurídico constante no parecer do Conselho Nacional de Educação CNE/CEB 36/2001, nas reflexões de Borges (2012) sobre a escola e prática docente no contexto rural e na proposta do programa da Etnomatemática de D'Ambrósio (2019) como recurso metodológico para ressignificar o ensino de matemática no contexto rural. Os resultados mostram que conforme o PPC do curso de Licenciatura em Matemática, a UEPA trabalha com uma proposta de formação docente com capacidade de autonomia intelectual com conhecimento da realidade sociocultural da região que é formado por uma considerada parcela de população rural. Os resultados revelam ainda que, embora o curso não seja específico para a Educação do Campo, há disciplinas em que o professor formador de professores pode problematizar e debater a realidade e desafios da educação para a população campesina.
\end{abstract}

Palavras-chave: Projeto Político Pedagógico, Licenciatura em Matemática, Contexto Rural. 


\title{
Degree in Mathematics from the University of the State of Pará - UEPA and training for teaching work in the rural context of Conceição do Araguaia - PA
}

\begin{abstract}
This article aimed to verify which aspects of teaching practice in the rural context are included in the Pedagogical Course Project (PPC) of the Mathematics Degree course at the State University of Pará - UEPA. To this end, a descriptive and documentary research was developed with a qualitative approach based on the analysis of the history of the legal system contained in the opinion of the National Council of Education CNE / CEB 36/2001, in the reflections of Borges (2012) on the school and teaching practice in rural context and in the proposal of D'Ambrósio's Ethnomathematics program (2019) as a methodological resource to resignify the teaching of mathematics in the rural context. The results show that the PPC of the Degree in Mathematics, UEPA works with a proposal for teacher training with the capacity for intellectual autonomy with knowledge of the socio-cultural reality of the region, which is formed by a considered portion of the rural population. The results reveal that, although the course is not specific to rural education, there are disciplines in which the teacher-educating teacher can problematize and debate the reality and challenges of education for the rural population.
\end{abstract}

Keywords: Political Pedagogical Project, Degree in Mathematics, Rural Context. 


\section{Licenciado en Matemáticas por la Universidad Estatal de Pará - UEPA y capacitación para el trabajo docente en el contexto rural de Conceição do Araguaia - PA}

RESUMEN. Este artículo tuvo como objetivo verificar qué aspectos de la práctica docente en el contexto rural están incluidos en el Proyecto del Curso Pedagógico (PPC) del curso de Grado en Matemáticas en la Universidad Estatal de Pará UEPA. Para este fin, se desarrolló una investigación descriptiva y documental con un enfoque cualitativo basado en el análisis de la historia del sistema legal contenido en la opinión del Consejo Nacional de Educación CNE / CEB 36/2001, en las reflexiones de Borges (2012) sobre la escuela y la práctica docente en contexto rural y en la propuesta del programa de Etnomatemáticas de D'Ambrósio (2019) como recurso metodológico para resignificar la enseñanza de las matemáticas en el contexto rural. Los resultados muestran que el PPC de la Licenciatura en Matemáticas, UEPA, trabaja con una propuesta de formación docente con capacidad de autonomía intelectual con conocimiento de la realidad sociocultural de la región, que está formada por una parte considerada de la población rural. Los resultados revelan que, aunque el curso no es específico para la educación rural, existen disciplinas en las cuales el maestro educador puede problematizar y debatir la realidad y los desafíos de la educación para la población rural.

Palabras clave: Proyecto Pedagógico Político, Licenciatura en Matemáticas, Contexto Rural. 


\section{Introdução}

Formação de Professores é uma linha de pesquisa educacional com grandes produções científicas no Brasil. Contudo, ainda é preciso avançar em pesquisas nessa área que contemple a atuação docente no contexto rural e o resultado dessas pesquisas precisa ser convertido em políticas públicas educacionais para a população campesina que, no decorrer da história da educação no Brasil, por muitas vezes foi negligenciada.

As regiões rurais são formadas por uma população que tem características próprias nos aspectos culturais, sociais e econômicos, que precisam ser reconhecidos e valorizados na educação. Nesse sentido, esse artigo inicia problematizando as políticas públicas para a população campesina que tradicionalmente foi esquecida na história do ordenamento jurídico brasileiro. Baseado nas reflexões de Borges (2012) sobre a escola e o trabalho docente no contexto rural, o texto faz referência ao papel protagonista do educador para conduzir o processo de ensino e de aprendizagem que para isso precisa ter atitudes conscientes de valorização das características e demandas da população do campo. Apresenta de forma sucinta o programa da etnomatemática como proposta pedagógica de ressignificar a prática do ensino de matemática no contexto rural.

O estudo finaliza com a apresentação da análise do Projeto Político do Curso de Licenciatura de Matemática da Universidade do Estado do Pará, ressaltando as disciplinas que apresentam temas que permitem abordar e contextualizar aspectos do contexto rural, concluindo com a percepção que o curso não contém direcionamento específico de formação docente para atuação nesse âmbito, porém seu currículo é composto por temas e conteúdos da Matemática e da Educação Matemática com implicações sociais, culturais e políticas que permitem ao professor formador de professores problematizar e debater a realidade, a demanda e os desafios da educação para a população campesina.

\section{Políticas públicas para a população campesina}

A população campesina é uma população tradicionalmente esquecida pelas políticas públicas brasileiras, principalmente no contexto educacional. Essa verdade fica evidente ao analisarmos o histórico do ordenamento jurídico brasileiro, as reformas educacionais brasileiras e a relevância das lutas dos 
movimentos sociais para obter garantia legal por uma educação no contexto rural.

O parecer do Conselho Nacional de Educação (CNE) CEB N 36/2001 sobre as Diretrizes Operacionais para a Educação Básica nas Escolas do Campo, apresenta um relatório cronológico sobre a política pública brasileira voltada para a Educação que atenda os interesses dos camponeses. Esse parecer ressalta que nos textos constitucionais de 1824 e 1891 não houve menção à Educação Rural e que a primeira vez a ser mencionada no ordenamento jurídico brasileiro foi nas primeiras décadas do século $\mathrm{XX}$, em um período em que havia debates sobre migração rural e a necessidade de elevar a produção no campo. Conforme esse parecer, a Constituição de 1934 cita o ensino nas zonas rurais no artigo $\mathrm{n}^{\circ} 156$, quando fala sobre o orçamento para manutenção dos sistemas educativos. Na constituição de 1946 e de 1967, transfere a manutenção do ensino nas zonas rurais para as empresas industriais, comerciais e agrícolas, sendo obrigadas a manter o ensino primário para os filhos dos trabalhadores. Já a Constituição Federal de 1988, destaca a educação como direito de todos e dever do Estado abrangendo, dessa forma, a população rural.

Ao analisarmos este levantamento histórico no Parecer, entendemos que as reformas na educação brasileira ao longo de sua história, também não consideraram a educação no campo. A Lei de Diretrizes e Bases da Educação Nacional (LDB), Lei n ${ }^{\circ} 4024 / 1961$, menciona o ensino rural nos artigos 32, 57 e 105, de forma superficial para falar respectivamente que os proprietários rurais, quando não pudessem manter escolas primárias para as crianças residentes deveriam facilitar a frequência dos mesmos em escolas próximas, sobre a formação de professores para as escolas rurais que poderiam acontecer em estabelecimentos que promovessem integração com o meio rural, e para falar da responsabilidade do poder público de auxiliar serviços e entidades que mantinham escolas em zonas rurais.

Na LDB de 1971, assim como na lei anterior, não inclui a educação para a população campesina como forma de reconhecimento de sua diversidade e integrante do conjunto da sociedade. O que trazia de diferente era o artigo $n^{\circ} 4$, onde o currículo poderia atender as particularidades da região rural e o artigo $\mathrm{n}^{\circ} 11$ onde o calendário escolar poderia ser alterado para considerar os períodos de plantio e de colheita de safras.

Analisar essa linha do tempo é importante para entendermos o quanto a educação rural foi voltada para os interesses do neoliberalismo, capitalismo, 
agronegócio e dos latifundiários, onde o ensino realizado nas zonas rurais geralmente é conduzido pelos mesmos princípios das escolas urbanas, sendo que o rural e o urbano possuem características diferentes e precisam ser trabalhados conforme suas particularidades.

A LDB - Lei 9394/96 foi a que trouxe certo avanço para a educação ruralista quando comparada com as demais reformas. O artigo $\mathrm{n}^{\circ} 28$ da Lei, dispõe que os sistemas de ensino adaptarão para se adequar às peculiaridades da população rural referente ao currículo, metodologia, calendário escolar e natureza do trabalho na zona rural. Contudo, adequar às peculiaridades da educação da população rural, compreende principalmente a adequação da formação e trabalho docente no contexto rural, por isso, as reformas educacionais precisam estudar e ouvir os educadores como sujeitos que conduzem o processo de ensino e aprendizagem, uma vez que "nenhuma reforma, seja ela qual for, tem o poder de mudar a realidade se não puder contar com os sujeitos que conduzem o processo." (Ghedin, 2012, p. 29).

\section{O Trabalho docente no contexto rural}

Após a promulgação da LDB $\mathrm{n}^{\circ}$ 9394/96, a população rural e os movimentos sociais, principalmente o
Movimento dos Trabalhadores Rurais Sem Terra - MST, através de reivindicações ao governo de políticas específicas para este segmento, tiveram conquistas significativas para educação da população do campo com o movimento da "Educação do Campo" e com o curso de "Licenciatura para a Educação do Campo", proporcionando assim uma formação específica para trabalhar com a realidade e as peculiaridades desse ambiente. Porém, muitas escolas públicas brasileiras, localizadas nas regiões rurais, ainda não atendem ao princípio da Educação do Campo e muitos professores que lecionam nas escolas rurais ainda são pessoas que vivem no meio urbano desvinculado da realidade de quem vive no campo.

Para Borges (2012), as escolas nos territórios rurais enfrentam diversos problemas dentre os quais destacamos a falta de estrutura necessária e docentes qualificados, currículo e calendário alheio à realidade do campo, muitos educadores com visão de mundo urbano onde a maioria não teve uma formação específica para trabalhar nesse contexto. "Na realidade, o fato da existência da Lei, não significa que podemos dizer que todas as escolas estão dentro dos princípios da Educação do Campo". (Borges \& Silva, 2012, p. 216). 
Para mudar essa realidade, mesmo com as conquistas educacionais, políticas e sociais para a população rural, as pessoas que estudam, trabalham e vivem no campo, precisam assumir o compromisso de aproximar a escola da formação humana e de sua comunidade, uma vez que a educação é o instrumento de transformação da realidade rural historicamente excluída.

Para Ribeiro (2012) a Educação Rural foi mobilizada para proporcionar o ensino e oferecer o conhecimento de leitura, escrita e operações matemáticas nos mesmos moldes da educação em áreas urbanas, ou seja, toda sua finalidade, programa, métodos e conteúdos são direcionados pelos interesses do setor industrial obrigando de certa forma, os alunos do campo, incorporarem a cultura do urbano. A Educação do Campo por sua vez, foi mobilizada a partir de outras motivações. Segundo Caldart (2012), ela nasceu de um movimento de reivindicação e resistência pela busca de valorização de suas escolas, experiências, territórios e identidade. Tem como princípios a luta social pelo acesso à educação dos trabalhadores do campo, luta por políticas públicas voltadas para essa classe, e combina a luta pela educação com luta pela terra, pela reforma agrária, pelo direito ao trabalho à cultura e ao território.
Essa distinção precisa ser problematizada para não ocorrer no equívoco de pensar a Educação do Campo como extensão da Educação Rural ou somente como mudança de nomenclatura. A Educação do Campo vislumbra a construção de identidade do homem do campo que luta pelo acesso e permanência na terra, e possui uma política de educação, formação de profissionais, estrutura e metodologia pedagógica específica que a distingue da simples educação rural.

Nesse contexto, o papel do professor precisa ser destacado, pois é ele o sujeito em formação que dirige o processo de educação. Os "educadores devem refletir sobre o modo de vida das comunidades para compreender melhor a realidade em que está inserida, incluir os saberes dominados por elas e promover o consenso entre saber popular e o saber científico". (Borges, 2012, p. 114).

Esse pensamento também é compartilhado por Dario Fiorentini (2016), pesquisador da área de Formação de Professores de Matemática que em uma entrevista concedida à revista Espaço Pedagógico afirmou que um dos desafios atuais da profissionalidade docente em matemática tem sido abrir espaço-tempo às múltiplas culturas e aos modos de significar das crianças e jovens que frequentam as escolas. Assim, a escola tem 
o desafio de garantir a formação matemática necessária para a inclusão cultural e social de seus estudantes. Para ele, somente a matemática formal não garante o engajamento da maioria dos estudantes e é preciso mobilizar outros modos de promover a relação do aprendiz com o saber matemático.

Considerando o contexto rural, a etnomatemática tem se apresentado como alternativa pedagógica para promover essa relação e ressignificar a prática do ensino de matemática no contexto rural. Ubiratan D`Ambrosio resume Etnomatemática como “a matemática praticada por grupos culturais, como comunidades urbanas e rurais, grupos de trabalhadores, classes profissionais, criança de uma certa faixa etária, sociedades indígenas e tantos outros grupos que se identificam por objetivos e tradições comuns aos grupos" $(2019$, p. 9).

A Etnomatemática como tendência metodológica conduz a abordagem dos conteúdos a partir das ideias matemáticas que eles já possuem. Valorizam e utilizam seus métodos, suas linguagens para contextualizar os conteúdos e fazer a relação com a matemática escolar, a exemplo da aferição de terra e o cálculo de área da superfície, a compra e venda de insumos com a matemática financeira e todo o saber-fazer matemático intrínseco no plantio, na colheita, no cultivo de animais, na produção de alimentos, na adubação, construção rural, dentre outros que transforma o ensino de matemático, tornando mais significativa e atrativa para os estudantes.

O campo e sua população têm uma história e cultura que precisa ser valorizada na educação para que se crie condições de vida e sobrevivência no campo sem haver necessidade de mudança para outra localidade em busca de outros meios de vida. A população campesina:

como todos os indivíduos e povos têm, ao longo de suas existências e ao longo da história, criado e desenvolvido instrumentos de reflexão, de observação, instrumentos teóricos e, associados a esses, técnicas, habilidades (teorias, techné, ticas) para explicar, entender, conhecer, aprender (matema), para saber fazer como resposta a necessidades de sobrevivência e de transcendência, em ambientes naturais, sociais e culturais (etnos) os mais diversos. (D'Ambrosio, 1996, p. 27).

Pensando no protagonismo do educador em dirigir o processo de aproximar a escola da formação do aluno, as alternativas metodológicas para conduzir o trabalho docente no contexto rural e a importância da matemática para o desenvolvimento cognitivo e formação do aluno enquanto cidadão, analisamos a formação de professores de matemática da Universidade do Estado do Pará sob perspectiva de atuação em espaços rurais 
no município de Conceição do Araguaia, interior do Pará.

\section{$O$ contexto da pesquisa}

Conceição do Araguaia é um município localizado no sudeste do Estado do Pará, e faz divisa com o estado do Tocantins. Possui 45.530 habitantes, sendo 32.437 habitantes nas áreas urbanas e 13.093 habitantes nas áreas rurais conforme o último censo realizado no ano de 2010 pelo Instituto Brasileiro de Geografia e Estatística (IBGE). O município também é marcado por histórias de grandes conflitos sociais e luta pela terra, o que resultou significativa quantidade de assentamentos. São "37 projetos de assentamento, com 4.270 famílias assentadas, numa área total de 227.193,62 ha, sendo que apenas um destes assentamentos foi desapropriado uma área de cerca de 60.000 hectares pertencente a um banco privado [sic]". (Ferreira, 2017. p. 148).

Conceição do Araguaia, conta com o privilégio de sediar três instituições de Ensino Superior sendo uma Universidade Estadual, um Instituto Federal e uma de Educação a Distância (EaD) de iniciativa privada. As três instituições ofertam cursos de Licenciatura, porém nenhuma oferta o curso de Licenciatura para a Educação do Campo para oferecer uma formação de professor específica para as particularidades da educação do campo.

Conforme levantamento realizado junto a Secretaria Municipal de Educação e Cultura (SEMEC), para atender a educação da população rural o município de Conceição do Araguaia conta com sete escolas municipais localizadas na zona rural e nove escolas municipais localizadas na zona urbana, mas que também atendem alunos do campo na Educação Infantil e Ensino Fundamental. Esse levantamento retrata a crítica de que é possível encontrar concepções de que a escola urbana é melhor que a rural, sob a visão do capital e que gera vários problemas como:

Estimuladora do abandono do campo por apresentar o urbano como superior, moderno, atraente; em muitos casos, trabalhando pela própria destruição, é articuladora do deslocamento dos alunos para estudarem na cidade, especialmente por não organizar alternativas de avanços das séries em escolas do próprio meio rural. (Borges, 2012, p. 108).

No quadro de professores da SEMEC, 12 professores são de matemática e todos estes formados pela Universidade do Estado do Pará - Campus de Conceição do Araguaia. Como não há no município a oferta de curso com formação específica para atuação na realidade e particularidades da população do campo como o curso de Licenciatura para a 
Educação do Campo, foi relevante analisar se a formação de professores de matemática da UEPA contempla aspectos da prática docente no contexto rural.

\section{Perfil e estrutura da Universidade do Estado do Pará}

Conforme o Plano de Desenvolvimento Institucional (PDI) 2017/2027, A UEPA é uma instituição pública de ensino superior mais interiorizada do estado do Pará e uma das mais interiorizadas no norte do País, formada por 20 campi sendo 15 no interior do estado. O campus de Conceição do Araguaia, criado em 1990 foi o primeiro núcleo de interiorização desta Instituição de Ensino Superior (IES) e atualmente contempla o Centro de Ciências Sociais e Educação e o Centro de Ciências Biológicas e da Saúde, ofertando 11 cursos sendo 2 na área da Saúde e 9 na área da educação, incluindo o curso de Licenciatura em Matemática.

Dentre os princípios norteadores das práticas acadêmicas dos cursos da UEPA apresentadas no PDI, três definem a garantia de que as práticas acadêmicas dos cursos ofertados no município de Conceição do Araguaia sejam flexíveis com as demandas da região, a fim de que o profissional formado nesta IES possa desenvolver suas atividades também no campo e contribuir para o desenvolvimento da região rural. São eles:

- Garantia da flexibilidade na aplicação de métodos, critérios e currículos, com o objetivo de atender às peculiaridades locais e a multidisciplinariedade;

- Formação de profissionais empreendedores nas diferentes áreas do conhecimento, aptos ao exercício profissional competente e a participação no desenvolvimento da sociedade em que interagem;

- Contribuição com a transformação da realidade regional com justiça social e desenvolvimento sustentável.

A política de ensino da UEPA é debatida no seu órgão consultivo e deliberativo, o Conselho Universitário (CONSUN) e está em consonância com as Diretrizes Curriculares Nacionais. Os Projetos Pedagógicos dos Cursos (PPC) são elaborados com participação da comunidade acadêmica, sendo produto da participação e do debate coletivo com a comunidade da UEPA. Projeto Pedagógico do Curso é "um instrumento dinâmico que trata sobre os movimentos educativos desenvolvidos pela Universidade, ao mesmo tempo engloba suas intencionalidades formativas que deverão ser contempladas nos currículos 
dos diversos cursos". (Universidade do Estado do Pará, 2017, p. 53).

Ainda segundo o PDI, a UEPA trabalha para formar alunos com perfil de egresso capacitado para analisar a sociedade com criticidade, ética, com capacidade de lidar, entender, intervir e atuar de forma a construir uma sociedade que respeita os princípios éticos, democráticos e culturais para formar $\mathrm{o}$ aluno do campo como cidadão capaz de transformar a realidade onde vive sem precisar ir para a cidade em busca de melhores condições de vida. Quanto a isso, Borges ressalta que:

Os educadores devem refletir sobre o modo de vida das comunidades para compreender melhor a realidade em que está inserido, incluir os saberes dominados por elas e promover o consenso entre o saber popular e o saber científico. Essa atitude consciente de valorização do outro contribui significativamente para a instauração e a construção de um processo democrático liderado pela escola. (Borges, 2012, p. 114).

Assim, o ensino de matemática nas escolas das regiões rurais de Conceição do Araguaia, deve ser realizado por educadores que reconhecem o conhecimento e o saber-fazer dos alunos campesinos. Que valorize o que eles já utilizam em suas práticas diárias e a partir disso, incluir o conhecimento científico. A partir desse entendimento, vamos analisar o Projeto Pedagógico do Curso de Matemática da UEPA e verificar se este contempla aspectos da prática docente no contexto rural.

\section{O Curso de Licenciatura em Matemática da UEPA e sua preparação para atuação no contexto rural}

A UEPA oferta o curso de Licenciatura em Matemática desde 02 de maio de 1989, quando ainda era Faculdade Estadual de Educação do Pará (FAED). Em 2001, com a política de interiorização da UEPA foi implantado o curso de Licenciatura em Matemática no Campus de Conceição do Araguaia com duas turmas iniciais. A implantação do curso se deu no sistema modular de ensino, como solução para interiorizar o Ensino Superior, selecionando os professores na capital para atuarem em forma de rodízio no interior do estado.

É importante observar que segundo o PPC do curso, a justificativa de interiorizar o Ensino Superior através da UEPA é consequência da amplitude geográfica do estado visando o compromisso de desenvolver as regiões do interior para que os formados pudessem permanecer no município que realizou a formação sem precisar migrar para a capital do estado, em busca de maiores oportunidades. Essa justificativa tem a mesma idealização da educação para a população campesina que 
precisa ser respeitada como uma população que tem características próprias e luta por uma política pública que incentive sua permanência e desenvolvimento do campo, e que sua identidade, cultura e saberes sejam valorizados.

O objetivo do curso é "Formar profissionais com habilitação em Licenciatura em Matemática, para exercerem com a devida competência, a docência do ensino da matemática e a pesquisa face à realidade dos fenômenos educacionais e suas múltiplas relações econômicas, políticas, sociais e culturais" (Universidade do Estado do Pará, 2012, p. 20).

O curso segue uma linha metodológica que se fundamenta em quatro Eixos Temáticos especificados no quadro abaixo:

Tabela 1 - Eixos Temáticos.

\begin{tabular}{|c|c|c|}
\hline $\begin{array}{c}\text { Eixos } \\
\text { Temáticos } \\
\end{array}$ & Ideia & Disciplinas \\
\hline $\begin{array}{l}\text { FUNDAMENTAÇÃO } \\
\text { MATEMÁTICA. }\end{array}$ & $\begin{array}{l}\text { A compreensão e a prática dos } \\
\text { diversos saberes na cultura } \\
\text { humana, particularmente o saber } \\
\text { matemático. }\end{array}$ & $\begin{array}{l}\text { - Fundamentos da Matemática } \\
\text { Elementar I; } \\
\text { - Fundamentos da Matemática } \\
\text { Elementar II; } \\
\text { - Geometria Analítica; } \\
\text { - Geometria Euclidiana; } \\
\text { - Álgebra I; } \\
\text { - Álgebra II; } \\
\text { - Análise Real; } \\
\text { - Cálculo I; } \\
\text { - Cálculo II; } \\
\text { - Cálculo Numérico; } \\
\text { - Desenho Geométrico; } \\
\text { - Teoria dos Números; } \\
\text { - História da Matemática; } \\
\text { - Estatística e Probabilidade; } \\
\text { - Física Geral. }\end{array}$ \\
\hline $\begin{array}{l}\text { FUNDAMENTAÇÃO } \\
\text { PEDAGÓGICA }\end{array}$ & $\begin{array}{l}\text { Possibilitar a compreensão dos } \\
\text { fundamentos e a prática dos } \\
\text { diversos saberes na cultura } \\
\text { humana }\end{array}$ & $\begin{array}{l}\text { - Didática Geral e Especial; } \\
\text { - Introdução à Educação } \\
\text { Matemática; } \\
\text { - Psicologia da Educação; } \\
\text { - Fundamentos da Avaliação da } \\
\text { Aprendizagem em Matemática; } \\
\text { - Políticas Públicas. }\end{array}$ \\
\hline $\begin{array}{c}\text { PRODUÇÃO DO } \\
\text { CONHECIMENTO }\end{array}$ & $\begin{array}{c}\text { Desenvolver a iniciação } \\
\text { científica, em grupo ou } \\
\text { individualmente, na perspectiva } \\
\text { transdisciplinar no decorrer de } \\
\text { toda a formação acadêmica. }\end{array}$ & $\begin{array}{l}\text { - Metodologia Científica; } \\
\text { - Comunicação em Língua } \\
\text { Portuguesa na Docência; } \\
\text { - Inglês Instrumental; } \\
\text { - Orientação de TCC I; } \\
\text { - Orientação de TCC II. }\end{array}$ \\
\hline
\end{tabular}




\begin{tabular}{|c|c|c|}
\hline PRÁXIS PEDAGÓGICA & $\begin{array}{l}\text { Promover a formação do } \\
\text { educador matemático com } \\
\text { fundamentação teórico-prática } \\
\text { bio-psico-social-cultural e } \\
\text { filosófica sobre educação. }\end{array}$ & $\begin{array}{l}\text { - Prática de Ensino de } \\
\text { Matemática I; } \\
\text { - Prática de Ensino de } \\
\text { matemática II; } \\
\text { - Instrumentação para o Ensino } \\
\text { da Matemática I; } \\
\text { - Instrumentação para o Ensino } \\
\text { da Matemática II; } \\
\text { - Educação Matemática e } \\
\text { Inclusão; } \\
\text { - Atividades Complementares. }\end{array}$ \\
\hline
\end{tabular}

Fonte: (Universidade do Estado do Pará, 2012)

O curso propõe uma formação onde a Matemática e a Educação Matemática sejam objeto de estudos em que as disciplinas pedagógicas sejam trabalhadas de forma simultânea e interligadas às de conteúdos específicos, "também deter-seão na especificidade da aquisição do conhecimento matemático, levando em consideração o desenvolvimento cognitivo e a diversidade dos grupos sociais" (Universidade do Estado do Pará, 2012, p. 19).

Com base na proposta do curso, e na definição do objetivo desse artigo de verificar no PPC e ementas das disciplinas, se o curso contempla aspectos da prática docente no contexto rural, analisamos quais disciplinas trazem em suas ementas temas que permitem abordar aspectos do contexto rural.

$\mathrm{Na}$ estrutura curricular do curso, na $1^{\text {a }}$ Série a disciplina "Introdução à Educação Matemática - 80h" apresenta na ementa o tema "Tendências da Educação Matemática" onde pode ser trabalhado o
Programa da Etnomatemática como uma das tendências atuais para o ensino de matemática. Tendência essa que, como já mencionado, tem se apresentado como alternativa pedagógica para fazer a relação da matemática aplicada nas comunidades rurais e a matemática escolar.

$\mathrm{Na} 1^{\circ}$ série também tem a disciplina de "Desenho Geométrico - 80h" que traz na ementa o tema "Aspectos sociais e culturais do desenho geométrico". Um tema relevante para compreender e interpretar as formas geométricas do espaço rural, suas relações e um recurso para a representação plana das mesmas. Para quem vive no campo e do campo, esse conteúdo é bastante utilizado para medir terra, trabalhar com agricultura, observar e interpretar figuras geométricas na natureza como na apicultura, altura e circunferência do tronco de uma árvore, por exemplo.

$\mathrm{Na} 4^{\mathrm{a}}$ série a disciplina "História da Matemática", visa conhecer a história da matemática e suas implicações sociais, culturais e políticas; e ainda a história do 
ensino de matemática nas civilizações e suas implicações. Quando se estuda a história da matemática, se verifica que há uma analogia com a matemática praticada no meio rural. Uma matemática descoberta e desenvolvida a partir das necessidades de resolução de problemas diários. Desde o período paleolítico inferior, o homem usa os conhecimentos matemáticos para atender suas necessidades sociais e de sobrevivência, assim como muitos homens e mulheres do campo, que muitas vezes não são alfabetizados, não sabem ler e escrever, mas tem algum conhecimento matemático que são utilizados nas suas atividades diárias. Conhecer a história e saber utilizar como recurso didático é muito importante até para motivar o ensino e a aprendizagem dos alunos da educação básica.

No mais, não encontramos outras disciplinas cujas ementas contemplam especificadamente aspectos da prática docente no contexto rural. Porém, além das apresentadas acima há outras três disciplinas que trazem em suas ementas temas que permitem contextualizar aspectos do contexto rural, o que depende muito da visão e estratégia do professor formador de professores ao elaborar o plano de ensino e assegurar esse assunto na formação de professores, já que na região há uma grande demanda de educação para o campo sendo relevante a problematização da educação no contexto rural, as quais são:

"Didática Geral e Especial - 80h" que segundo a ementa dá ênfase no ensino para a descoberta e na solução de problemas, já que o ensino no contexto rural precisa ser muito dinâmico. Não há como realizar um ensino estático no meio rural, os alunos precisam ter uma aprendizagem significativa e relacionada com seu modo de vida. A matemática escolar precisa ter relação com a matemática que eles usam diariamente para ter sentido.

"Prática de Ensino de Matemática I 200h" e "Prática de Ensino de Matemática II - 200h" que são os Estágios Supervisionados em que os acadêmicos podem vivenciar a realidade escolar no ensino fundamental e ensino médio. "O objetivo da Prática de Ensino é propiciar ao aluno sua inserção na realidade sóciopolítico-econômico e cultural" (Universidade do Estado do Pará, 2012, p. 28). É uma oportunidade de aplicação dos conhecimentos construídos no decorrer da formação. Nessa disciplina os alunos que se identificam com a educação no contexto rural podem realizar Estágio nessa localidade e vivenciar a prática docente desde o período da formação inicial e buscar aprimoramento na área. 
O PPC também apresenta a exigência de 200 horas/aulas de Atividades Complementares para integralização do curso. Essas atividades objetivam complementar a formação acadêmica do aluno na práxis educativa dentre as opções constantes em uma tabela de co-validação que vai desde a participação em eventos científicos à participação em pesquisas e atividades de extensão, são oportunidades do acadêmico, futuro professor de matemática realizar atividades que tem afinidade.

\section{Considerações finais}

Com base no que foi analisado no PPC do curso de Licenciatura em Matemática da UEPA, o curso não contempla formação docente específica para atuação no contexto rural, porém é uma proposta de formação com capacidade de autonomia intelectual com conhecimento da realidade sociocultural da região.

Sua proposta pedagógica condiz com uma formação onde o professor é o estimulador e motivador do processo de ensino e de aprendizagem e com uma política de ensino que favorece a construção da identidade do professor onde seus conhecimentos não são fundamentados somente no que é visto em sala de aula, mas também naquilo que ele produz durante a formação a fim de formar um docente autor da sua profissão.

Seu desenho curricular é composto por temas e conteúdos da Matemática e da Educação Matemática com implicações sociais, culturais e políticas que permitem ao professor formador de professores problematizar e debater a realidade, demanda e desafios da educação para a população campesina, uma vez que o Campus de Conceição do Araguaia está localizado em uma região com grande participação da população rural, muitos alunos podem ser advindos dessas regiões e, o levantamento realizado junto a SEMEC, o lugar de atuação dos futuros professores pode ser em escolas ruralistas ou escolas urbanas mas que atendem alunos vindos das regiões rurais.

Por isso a importância de tratar temas que discutem toda a história da educação ruralista e o papel que as instituições de ensino superior e movimentos sociais têm exercido na região para garantir o direito a educação para a população do campo.

Os estudos realizados nesse artigo ficam como introdução de uma investigação que pode avançar. É preciso realizar um estudo que investigue a atuação docente no contexto rural, qual contribuição a formação inicial proporcionou para a atuação profissional nesse contexto, se há formação continuada 
para preparar o docente para trabalhar nesse contexto, proporcionando o desenvolvimento cultural, político e econômico dessa parcela da população.

\section{Referências}

Borges, H. S., \& Silva, H. B. (2012). Educação do Campo e a Organização do Trabalho Pedagógico. In Ghedin, E. (Org.). Educação do Campo: Epistemologia e Práticas (pp. 206-235). São Paulo, SP Cortez.

Borges, H. S. (2012). Educação do Campo como processo de luta por uma sociedade justa. In Ghedin, E. (Org.). Educação do Campo: Epistemologia e práticas (pp. 76116). São Paulo, SP: Cortez.

Caldart, R. S. (2012). Educação do Campo. In Caldart, R. S. (Org.). Dicionário da Educação do Campo (pp. 257-267). São Paulo, SP: Escola Politécnica de Saúde Joaquim Venâncio, Expressão Popular.

Ribeiro, M. (2012). Educação Rural. In Caldart, R. S. (Org.). Dicionário da Educação do Campo (293-301). São Paulo, SP: Escola Politécnica de Saúde Joaquim Venâncio, Expressão Popular.

D'Ambrosio, U. (1996). Educação Matemática: da teoria a prática. Campinas, SP: Papirus.

Ferreira, L. (2017) A Compreensão Histórica e Folclórica Pela Cartografia Social: um estudo de caso do município de Conceição do Araguaia - Pará. RETTARevista de Educação Técnica e Tecnológica em Ciências Agrícolas, 8(15), 146-165.

Fiorentini, D. (2016, 30 março). Diálogos com Educadores. Espaço Pedagógico, 20(1), 217-227.
Ghedin, E. (2012). Perspectivas Sobre a Identidade do Educador do Campo. In Ghedin, E. (Org.). Educação do Campo: Epistemologia e Práticas (pp. 25-62). São Paulo, SP: Cortez.

Instituto Brasileiro de Geografia e Estatística. (2020). Censo Demográfico 2010. Pará: IBGE, Recuperado de https://cidades.ibge.gov.br/brasil/pa/concei cao-do-araguaia/panorama

Lei n. 9.394 de 20 de dezembro de 1996. (1996, 20 de dezembro). Estabelece as Diretrizes e Bases da Educação Nacional. Recuperado de: http://www.planalto.gov.br/ccivil_03/leis/1 9394.htm

Parecer CNE/CEB n ${ }^{\circ} 36$ de 4 de dezembro de 2001 (2001, 4 de dezembro). Diretrizes Operacionais para a Educação Básica nas Escolas do Campo Parecer CEB $\mathrm{n}^{\circ}$ 36/2001, 04 de dezembro de 2001.

Universidade do Estado do Pará. (2012). Projeto Pedagógico do Curso de Licenciatura em Matemática. Belém, PA: UEPA.

Universidade do Estado do Pará. (2017). Plano de Desenvolvimento Institucional 2017-2027. Belém, PA: UEPA.

Informações do artigo / Article Information

Recebido em : 22/04/2020

Aprovado em: 01/08/2020

Publicado em: 25/11/2020

Received on April 22th, 2020

Accepted on August 01st, 2020

Published on November, 25th, 2020

Contribuições no artigo: Os autores foram os responsáveis por todas as etapas e resultados da pesquisa, a saber: elaboração, análise e interpretação dos dados; escrita e revisão do conteúdo do manuscrito e; aprovação da versão final publicada. 
Silva, K. F., \& Vizolli, I. (2020). Licenciatura em Matemática da Universidade do Estado do Pará - UEPA e a formação para o trabalho docente no contexto rural de Conceição do Araguaia - PA...

Author Contributions: The author were responsible for the designing, delineating, analyzing and interpreting the data, production of the manuscript, critical revision of the content and approval of the final version published.

Conflitos de interesse: Os autores declararam não haver nenhum conflito de interesse referente a este artigo.

Conflict of Interest: None reported.

Orcid

Kamilla Ferreira da Silva

(iD) http://orcid.org/0000-0002-7853-4315

Idemar Vizolli

(iD) http://orcid.org/0000-0002-7341-7099

\section{Como citar este artigo / How to cite this article}

APA

Silva, K. F., \& Vizolli, I. (2020). Licenciatura em Matemática da Universidade do Estado do Pará - UEPA e a formação para o trabalho docente no contexto rural de Conceição do Araguaia - PA. Rev. Bras. Educ. Camp., 5, e9000. http://dx.doi.org/10.20873/uft.rbec.e9000

ABNT

SILVA, K. F.; VIZOLLI, I. Licenciatura em Matemática da Universidade do Estado do Pará - UEPA e a formação para o trabalho docente no contexto rural de Conceição do Araguaia - PA. Rev. Bras. Educ. Camp., Tocantinópolis, v. $5, \quad$ e9000, 2020. http://dx.doi.org/10.20873/uft.rbec.e9000 